\title{
Fish aggregation device (FAD) research: gaps in current knowledge and future directions for ecological studies
}

\author{
Tim Dempster ${ }^{1 *}$ and Marc Taquet $^{2}{ }^{3}$ \\ ${ }^{1}$ School of Biological Sciences, University of Sydney, New South Wales, Australia, 2006 \\ ${ }^{2}$ IFREMER, Laboratoire Ressources Halieutiques, Rue Jean Bertho, B.P. 60, 97822 Le Port Cedex, Ile de la \\ Réunion, France \\ ${ }^{3}$ Ecole Pratique des Hautes Etudes, URA 1453 CNRS, Université de Perpignan, 66860, Perpignan, Cedex, \\ France \\ *: Corresponding author : Phone: +46-90-196-056 empster tim@hotmail.com
}

\begin{abstract}
We reviewed the literature concerning fish aggregation devices (FADs) to determine areas of relative research deficiency. Using specific searches of the Aquatic Sciences and Fisheries Abstracts (ASFA) database from 1978 to December 2003 and a classical search of the pre-1978 literature, we collected 407 references on FADs. Publications before 1980 were predominantly peerreviewed, although non-peer reviewed literature has dominated since 1980, due to the numerous technical reports produced as FADs became more widely used in artisinal and large-scale industrial fisheries in the 1980s. Most studies of the ecology of FAD-associated fish were descriptive, with few mensurative experimental studies and even fewer manipulative experimental studies that tested specific hypotheses, due to inherent difficulties in working in the open ocean on objects that are temporary in space and time. Research on the ecology of FAD-associated fish has focused on moored FADs, despite the major FAD-based fisheries being around drifting FADs. Publications presenting information on moored FADs outnumbered papers on drifting FADs by a ratio of 3.5:1. We recommend that greater emphasis be placed by fisheries scientists and funding agencies on researching drifting FADs to provide better information for management of large-scale FAD-based industrial fisheries. Future research should focus on determining the patterns of use of drifting FADs by pelagic species, the underlying sensory processes of attraction and the ecological consequences for individual fish stocks and the wider pelagic ecosystem of the use of FADs as fisheries enhancement tools.
\end{abstract}

Keywords: association - Fish Aggregation Device - FAD - literature review - pelagic fish - tuna 


\section{Introduction}

Structures that float on the surface of the ocean attract both juvenile and adult fishes in great numbers and diversity (Kingsford 1993, Parin and Fedoryako 1999, Castro et al. 2002). Aggregations of fishes have been recorded extensively around both natural drifting objects, such as logs (Greenblatt 1979), jellyfish (Manseuti 1963, Broduer 1998) and drift algae (Ida et al. 1967, Safran and Omori 1990, Kingsford 1992, 1995), and artificial floating structures, that may be either moored or drifting, including rubbish (Riera et al. 1999), rafts (Heyerdahl 1950), man-made fish aggregation devices (FADs, Higashi 1994), oil platforms (Franks 2000), and coastal sea-cage fish farms (Dempster et al. 2002, Boyra et al. 2004). While FADs have traditionally been defined as objects placed in the ocean specifically to attract fish for capture, for the purpose of this review we refer to all of the above structures as fish aggregation devices (FADs).

Association with floating structures in open waters during one or more life history stages has been recorded for 333 fish species belonging to 96 families (Castro et al. 2002), although strong evidence of association exists for far fewer species (Kingsford 1993). Association with floating structures is displayed by fish of almost all ontogenetic stages (Parin and Fedoryako 1999), from small post-flexion juveniles (Hunter and Mitchell 1967, Kingsford 1992) to large adults (Kojima 1956, Greenblatt 1979). As the behaviour is so pervasive, it is likely to have a significant adaptive advantage, although the evolutionary mechanisms driving association may differ with species, life history stage and structure type (Fréon and Dagorn 2000, Castro et al. 2002).

FADs are used widely in tropical and semi-tropical waters by recreational, artisinal and commercial fishers, to concentrate pelagic fish for capture. While artisinal fishers have known and used such associations for hundreds (e.g. Japan, Kakuma 2000a) to thousands (e.g. Mediterranean Sea, Morales-Nin et al. 2000) of years, large-scale industrial fishing around FADs developed in the latter part of the $20^{\text {th }}$ century (Fonteneau et al. 2000b). Currently, approximately 1.2 million tons of the three main species of tuna (yellowfin, skipjack and bigeye) that associate with drifting FADs and over 100000 tons of by-catch are caught each year in the Atlantic, Indian and Pacific oceans (Alain Fonteneau, pers. comm.), which is approximately $1.5 \%$ by weight of the world's capture fishery each year (FAO 2002). The extent of catches around moored FADs is unknown (Alain Fonteneau, pers. comm.), but is a fraction of that taken around drifting FADs.

Historically, the idea of grouping fish around floating structures to improve catches comes from traditional coastal fishing. The earliest known use of FADs dates back to $200 \mathrm{AD}$ in the Mediterranean, when the Roman author Oppian described the use of FADs to catch dolphinfish (cited in Pepperell 2001). The use of similar aggregating devices, anchored 'tsukegi' rafts, to catch dolphinfish (Coryphaena hippurus) and amberjack (Seriola quinqueradiata) had also developed in Japan by 1650 (Nakamae, 1991). In Indonesia, Malaysia and the Philippines, traditional bamboo rafts anchored close to the coast called 'rumpon', 'unjang' and 'payao' respectively (Bergstrom, 1983), have been used since the beginning of the $20^{\text {th }}$ century to attract small pelagic fish (Anderson and Gates, 1997).

In the Pacific, the American tuna fleet began to fish with purse seines around drifting logs in 1976 (Marcille 1979). The development of this technique probably influenced the deployment of the first moored FADs in Hawaii in 1977 (Matsumoto et al., 1981) and the program that began in 1980 and continues today (Higashi 1994, Holland et al. 2000). 
According to Preston (1991), the success of moored FADs in Hawaii and the Philippines sparked development of moored FAD programs throughout the South Pacific.

The justification for the development of many FAD programs has been to shift fishing pressure towards pelagic fish in areas where bottom fish were over-exploited (Taquet 1998, Kakuma 2000a) or to diversify regional or national fishing activity. However, greatly increased use of FADs (both moored and drifting) in pelagic fisheries over the past decade has dramatically shifted patterns of stock exploitation. Larger catches of smaller tuna around FADs could lead to recruitment overfishing of some tuna stocks (Fonteneau et al. 2000b). Moreover, increased use of artificial moored and drifting FADs in the world's oceans represents a modification of the pelagic habitat, which could produce ecological changes such as altering migration paths, growth and predation rates for pelagic species (Taquet et al. 2000, Marsac et al. 2000, Essington et al. 2002). Fonteneau et al. (2000b) estimated that the total number of drifting FADs employed worldwide by industrial purse seiners is in the tens of thousands, and moored FADs are used extensively (28 countries, Fréon and Dagorn 2000) in the Pacific (e.g. Desurmont and Chapman 2000, Holland et al. 2000, Kakuma 2000a), Indian (e.g. Tessier et al. 2000) and Atlantic oceans (e.g. Reynal et al. 2000, Morales-Nin et al. 2000). With such important ecological and fisheries management implications regarding the increased use of FADs, targeted research into the ecology of FAD-associated species that will aid management is essential.

Research on FADs over the past 30 to 40 years has taken many directions, although the great majority of effort has focused on development of FAD-based fisheries. Despite much interest, little is known of the evolutionary mechanisms driving association and the ecological interactions of fish with FADs. Several hypotheses have been proposed to explain why fish are attracted to FADs (reviews: Fréon and Dagorn 2000, Castro et al. 2002) and how fish detect FADs (e.g. Holland et al. 1990, Dempster and Kingsford 2003). While research has provided much observational evidence on the relative importance of some theories, few studies have tested specific hypotheses with rigorous experimental designs and appropriate controls (Kingsford 1999). Sensory cues and processes that enable pelagic fish of all ontogenetic stages to both detect and remain associated with floating structures have also received little research attention.

Here we critically review the available scientific and non-scientific literature concerning FADs. Our aim was twofold: to identify areas concerning the use and effects of FADs that had been appropriately tested and documented and to indicate areas where our understanding is poor and future research is necessary. The results should serve to focus attention on emerging areas of research on FAD use and the ecology of FAD-associated fish.

\section{Methods}

The study is based on a comprehensive search of the literature available through the Aquatic Science and Fisheries Abstracts (ASFA) database, together with a classical search of the literature, to construct a database of specific research on FADs (hereafter called FADbase). The ASFA database from 1978 to December 2003 contains over 300000 references. Searches for keywords and combinations of keywords were run with Ovid. We made single keyword searches using 'FAD(s)', 'Fish Attraction Devices(s)', 'Fish Aggregation Device(s)', 'Fish Aggregating Device(s)' and DCP(s) (French abbreviation for FAD). Further, to include the literature on tuna aggregations around floating logs that may not 
have appeared under FAD-based keywords, searches for 'driftwood', 'floating object(s)' and ' $\log (\mathrm{s})$ ' were run. References prior to 1978 were obtained through a classical search of the literature. We acknowledge that some of the literature, particularly non-peer reviewed publications, may not have been discovered by our search. However, we made particular effort to obtain published scientific papers that contained information concerning FADs. We also took care to include the large amount of literature in French. Where more than one reference by the same author clearly presented the same information, only one was included, with a peer reviewed paper given preference over a non-peer reviewed publication.

Papers identified by the search were read and those that provided minimal information on FADs were not included in the database. Our search revealed a total of 407 papers over the period from 1960 to 2003. Data obtained from each paper included year of publication, peer reviewed or non-peer reviewed literature, oceanic region, primary study species, study duration, FAD type (drifting natural, drifting artificial or moored artificial), study approach (review, descriptive, mensurative experimental, manipulative experimental, theoretical), primary topic and experimental or sampling method. Where papers covered several topics, we designated the primary topic as the area treated with greatest attention by the author. Not all papers gave information for each category. FADbase is freely available in downloadable form at www.ifremer.fr/dcp and will be updated annually so it can serve as an ongoing resource for FAD scientists.

Throughout the review, the terms 'intranatant', 'extranatant' and 'circumnatant' follow Freon and Dagorn's (2000) revised definitions of those first proposed by Parin and Fedoryako (1999). The term 'FAD-associated tunas' refers to the three major species of tuna that associate with FADs: yellowfin (Thunnus albacares), skipjack (Katsuwonus pelamis) and bigeye (T. obesus).

\section{Literature analysis}

Trends in publication number and type over time

The majority of publications on FADs were non-peer reviewed articles $(\mathrm{n}=249)$ compared to peer-reviewed papers $(n=158)$. Publications concerning FADs prior to 1980 were predominantly peer-reviewed (Figure 1). A steep increase in the number of non peerreviewed technical reports occurred thereafter as drifting FADs became the basis of major commercial tuna fisheries from the early 1980s and development of moored FAD programs occurred worldwide, sparked by the successful deep-water FAD program in Hawaii (Higashi 1994). Non-peer reviewed literature dominated over the 20 years from 1980 to 1999, with three articles published for every peer-reviewed publication. A large number of peer-reviewed papers were produced in 1999 and 2000, following publication of the proceedings of international symposiums on dolphinfish (Massuti and Morales-Nin 1999) and FADs (Le Gall et al. 2000). 
Fig. 1 Number of peer and non-peer reviewed publications concerning fish aggregation devices from 1960 to 2003.

Dempster and Taquet Fig. 1

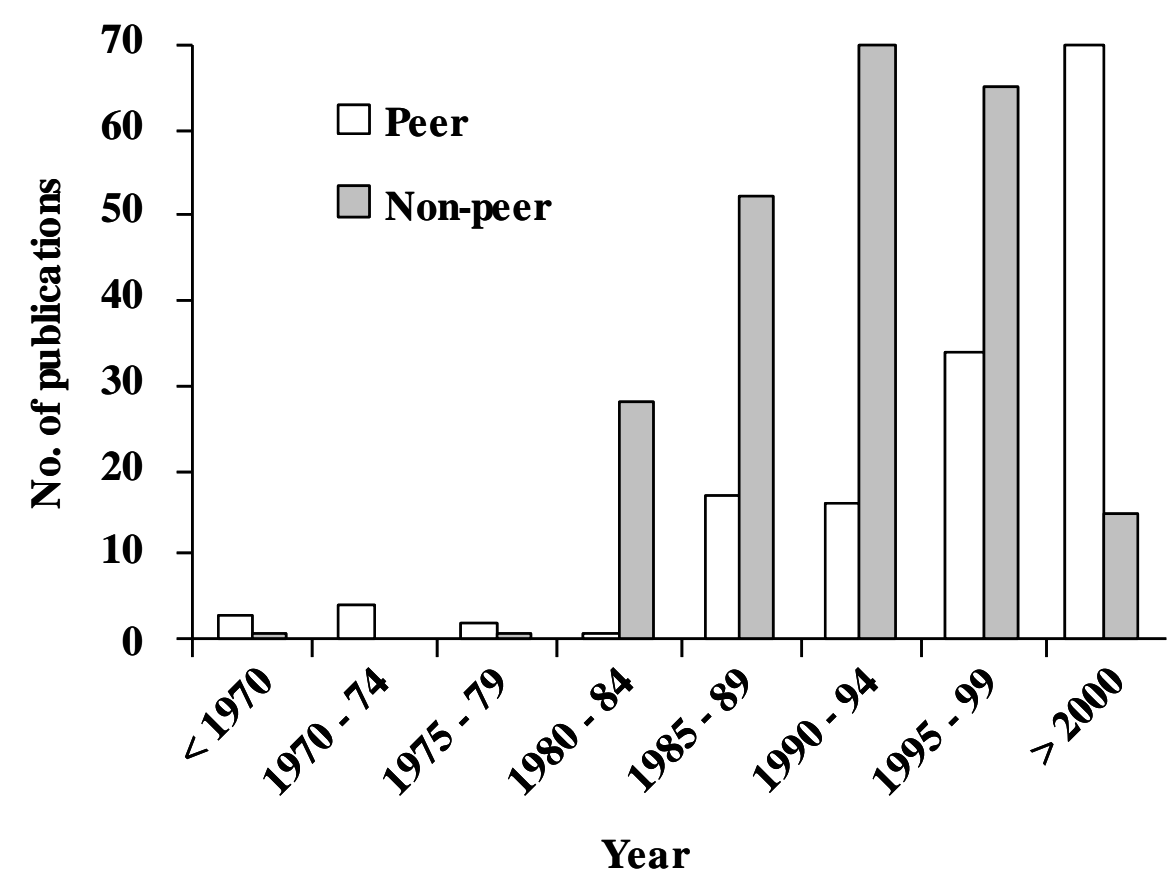

Primary topics, study approaches and study techniques

While the level of understanding in a particular subject area cannot be quantified in terms of absolute numbers of papers written, our analysis highlights areas where comparatively little research has been undertaken. Primary topics of papers were categorized into 4 broad areas: general papers, fishery enhancement, biological studies and management issues (Table 1). General papers were most numerous and included program descriptions ( $\mathrm{n}=$ $67)$, broad descriptions of the use of FADs $(n=66)$ or review articles $(n=24)$. Studies that were classified into the use of FADs for fishery enhancement category were predominantly concerned with fisheries production at FADs $(\mathrm{n}=33)$, design, construction and deployment ( $\mathrm{n}$ $=24)$, FAD type or position $(n=11)$ and fishing techniques at FADs $(n=11)$. Biological studies were dominated by research of the attraction of fish to FADs $(n=50)$, effects of fishing at FADs on fish stocks $(n=23)$ and studies of the movements of FAD-associated fish $(n=23)$. Papers concerning the diet of FAD-associated fish $(n=10)$ were comparatively few. Of the handful of papers dealing primarily with by-catch of FAD-based fisheries, the majority are recent publications (5 of 6 after 1998), highlighting the emerging nature of this area of research. Numerous articles were categorised as having management related issues as a primary focus, with economics related to the introduction or use of FADs $(n=19)$ and general management issues $(n=12)$ receiving some attention. 
Table 1 Number of studies on fish aggregation devices with primary topics in particular research areas.

\section{$\begin{array}{lll}\text { Research areas and primary topics } & \text { No. } & \text { Examples }\end{array}$}

General papers: $\quad$ Program descriptions 67

Holland et al. 2000, Kakuma 2000a

Use of FADs 66

General or review articles $\quad 24$

Fonteneau et al. 2000b, Castro et al. 2002

Bibliographies 2

Vega 1988

Fishery enhancement: Production of FADs 33

Fishery techniques 11

FAD type or position 11

Design, construction and deployment $\quad 24$

Longevity/Loss 3

Biological studies: Attraction of fish to FADs 50

Experimental designs 1

Movements 23

Diet 10

Effects of FAD fishery on population $\quad 23$

By-catch 6

General biology 12

Distribution of FADs 4

Management issues:

Legal issues 3

Economics 19

Training 3

General management issues 12
Wickham et al. 1973, Buckley et al. 1989

Chapman 2000

D’Anna et al. 1999

Higashi et al. 1994

Sacchi and Tessier 2000

Hunter and Mitchell 1967, Castro et al. 1999

Kingsford 1999

Holland et al. 1990, Dagorn et al. 2000a

Brock et al. 1985, Menard et al. 2000

Fonteneau et al. 2000a, Essington et al. 2002

Au 1991, Romanov 2002

Dempster 2004

Solana-Sansores 2001

Cayre et al. 1991

Ray-Valette et al. 2000

Ahilan et al. 1995

Yahaya 1994 
Papers took a descriptive approach on most occasions (63\%), with comparatively few testing specific hypotheses with mensurative (10.9\%) or manipulative $(7.3 \%)$ experimental approaches (Table 2). Of those studies that presented data $(n=233$, Table 3), 45.3\% relied upon fishery dependent information such as catch and effort and as such few had appropriate controls. Other widely used techniques to study FADs and the fishes associated with them included visual counts (10.7\%), fishery independent catch data (e.g. experimental trolling (8.6\%), ultrasonic and archival tags (7.3\%), modelling (6.9\%), and experimental net sampling $(6.4 \%)$.

Table 2 Approaches used by studies of fish aggregation devices from 1960 to 2003. Man. exp $=$ manipulative experiment, Mens. exp $=$ mensurative experiment.

\begin{tabular}{ccc}
\hline Approach & No. of studies & \% of total \\
\hline Bibliography & 2 & 0.5 \\
$\begin{array}{c}\text { Descriptive } \\
\text { Mens. exp } \\
\text { Man. exp }\end{array}$ & 242 & 63.0 \\
Man. exp & 28 & 10.9 \\
Management & 12 & 7.3 \\
Review & 36 & 3.1 \\
Theoretical & 22 & 9.4 \\
\hline
\end{tabular}

Research by oceanic region and primary study species

The areas where research was conducted were divided into the three major oceans (Pacific, Atlantic, Indian) and the three discrete areas of southeast Asia, the Caribbean and the Mediterranean Sea. Most studies were conducted in the Pacific Ocean ( $n=136,39.4 \%)$, with fewer studies in the Indian $(n=64,18.6 \%)$ and Atlantic Oceans $(n=31,9.0 \%)$. The Caribbean $(n=63,18.3 \%)$, southeast Asia $(n=28,8.1 \%)$, and the Mediterranean Sea $(n=23$, $6.7 \%$ ) were all relatively well studied regions given their small areas compared to the ocean basins. Research in these 3 regions was almost exclusively focused on moored FADs used for local small scale fisheries.

Species of tuna were the primary research taxa of the majority of FAD-related papers, comprising 53.3\% ( $n=145$ papers) of all research effort $(n=272$ papers that gave study species). Many papers ( $n=85,31.3 \%$ ) provided information on two or more of the three major FAD-associated tuna species (Katsuwonus pelamis, Thunnus albacares and T. obesus). Most of these papers were concerned with description of the FAD-based fishery for these major commercial species. Publications that presented information specifically relating to one tuna species were fewer, with $T$. albacares $(n=37,13.6 \%)$ the species of choice for research 
more often than both $K$. pelamis $(\mathrm{n}=15,5.5 \%)$ and $T$. obesus $(\mathrm{n}=8,2.9 \%)$. Studies that focused on the entire community of juvenile and adult fish found at FADs ( $n=39,14.3 \%$ ) or the community of large pelagic species apart from tuna $(n=56,20.6 \%)$ were also numerous. Dolphinfish (Coryphaena hippurus) were also the principal focus of a significant group of studies $(\mathrm{n}=18,6.6 \%)$.

\section{Research by FAD type and study duration}

Publications that contained information on moored FADs $(n=268)$ outnumbered publications on drifting FADs $(n=76)$ by a ratio of over 3.5:1. Analysis of the duration of data sets presented by publications on moored and drifting FADs (natural and artificial) indicated that the type of research produced varied greatly by FAD type (Figure 2). A far greater number of short- ( $<1$ year) and medium-term (1 to $5 \mathrm{yr}$ ) data sets were produced on moored FADs than on natural and artificial drifting FADs. Short- and medium-term studies tended to contain ecological information on FAD-associated species. The relative lack of short- and medium-term studies on drifting FADs may reflect difficulties in working on objects that are variable in space and time. Long-term studies for both drifting and moored FADs were typically syntheses of fisheries dependent data on FAD-based fisheries.

Fig. 2 Number of publications presenting short ( $<1 \mathrm{yr}$ ), medium (1 to $5 \mathrm{yr}$ ) and long ( $>5 \mathrm{yr}$ ) term data sets for drifting artificial, drifting natural and moored fish aggregation devices from 1960 to 2003.

Dempster and Taquet Fig. 2

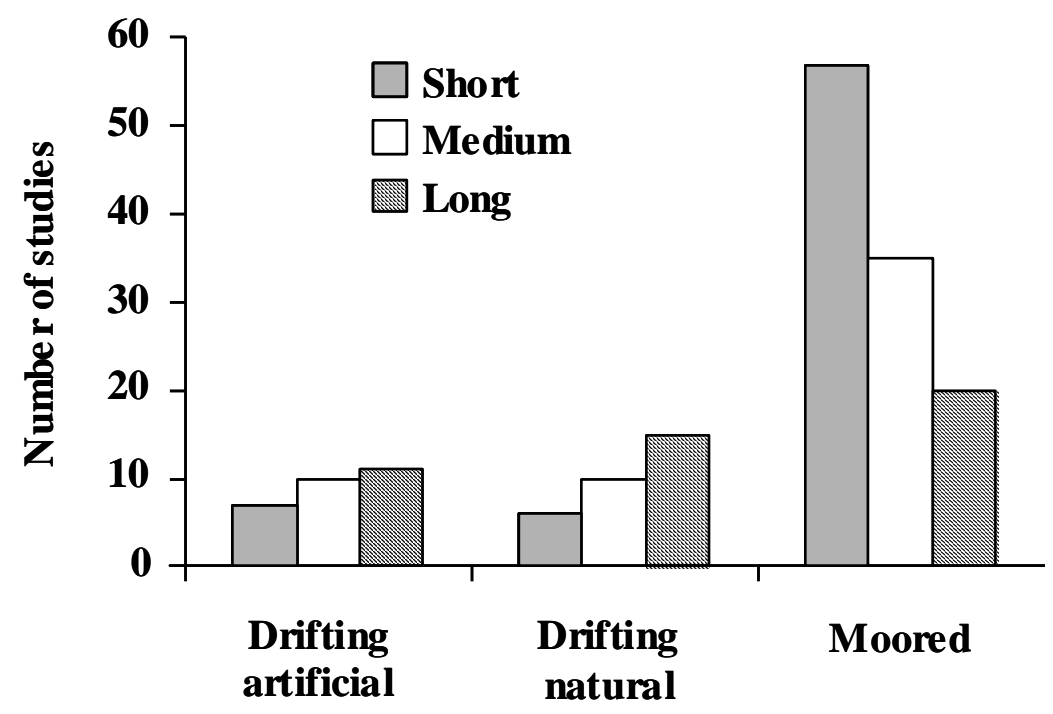




\section{Perspectives on current knowledge and future research}

\section{Technological development of moored and drifting FADs}

Moored FADs are used in over 28 countries around the world (Fréon and Dagorn 2000). Designs vary widely (Le Gall et al., 2000) from large (steel surface buoy $=7 \mathrm{~m}$ deep, 16 m wide), expensive (\$1 million US), highly durable FADs in Okinawa, Japan (Kakuma 2000a) to small, light, inexpensive ( $\approx$ \$300 US) FADs such as those deployed in Guadeloupe (Lesser French Antilles, Gervain pers. comm.). Between these two extremes, many different designs exist; however, we can split moored FADs into 3 broad categories: heavy, semi-heavy and light FADs.

Heavy FADs generally have only one large surface buoy made of steel, such as those in use in Hawaii (Holland et al. 2000), the South Pacific Islands (Desurmont 2000), Guam (Torres 2000) and Japan (Kakuma 2000a), or of PVC, such as those in Curaçao (van Buurt 2000). In some countries, like French Polynesia, steel surface buoys have been progressively replaced by PVC buoys (Leproux 2000). Foam-filled tyre buoys, drums (steel or plastic) and fiberglass surface buoys have also been trialed as surface buoys over the past two decades (Biais and Taquet 1990a, Wendling and Le Calvé, 2000).

Heavy FADs are generally moored with a single line consisting of different portions: chain or wire cable near the surface to protect the device from boat and fishing line damage, nylon rope (negative buoyancy) in the mid-section of the mooring line and polypropylene rope (positive buoyancy) in the lower section connecting to the anchor. These different ropes (diameter $\phi \approx 25 \mathrm{~mm}$ ) form an inverse catenary system of the type described by Boy and Smith (1984) and Gates et al. (1996). The mooring line to mooring depth ratio is generally between 1.3:1 and 1.5:1. Anchors are typically made of one to three concrete blocks, with the total relative weight of the anchor system greater than the total buoyancy of the FAD.

Semi-heavy FADs were initially deployed in the Indian Ocean around Mauritius (Roullot et al. 1988), Reunion Island (Biais and Taquet 1990b), and Mayotte (Minet and Taquet 1993). Unlike heavy FADs, the surface float consists of many pressure resistant buoys that sink progressively with strong currents and return to the surface after long periods of immersion. As this type of FAD has proved to be particularly long lasting, it has been adopted in both the Caribbean (Guillou et al. 1995, Taquet 1998) and throughout the South Pacific islands (Desurmont 2000). The mooring line systems and components of semi-heavy FADs are very similar to heavy FADs, with a similar mooring line to depth ratio but a smaller rope diameter (12 $\mathrm{mm}<\phi<18 \mathrm{~mm})$.

The designs and components of light FADs are extremely varied. Fishers themselves often build them with recovered buoys and easily accessible, cheap materials. Bamboo has been used for hundreds of years in Japan to construct light FADs named 'tsukegi' (Kaneda, 1986). Similarly, 'rumpong' in Indonesia, 'unjang' in Malaysia (Bergstrom 1983) and 'payao' in the Philippines (Murdy 1980) are also built with bamboo and coconut fronds. In the Mediterranean, light FADs built with cork floats and palm fronds are numerous and are used seasonally to exploit young dolphinfish (Coryphaena hippurus) in the 'kannizzati' fishery on Malta (Galea 1961), the 'capcer' fishery on Majorca and the 'cannizzi' fishery on Sicily (Morales-Nin et al. 2000). 
Even if the light FADs used throughout Asia and the Mediterranean Sea are the conceptual predecessors of modern moored FADs, the widespread use of semi-heavy and heavy FADs is not the result of technological evolution, as the use of light FADs remains popular. Rather, the type of FAD used in a particular area (light, semi-heavy or heavy) corresponds to a trade-off between expense and longevity, without any direct link to the aggregating efficiency of FADs. In recent years, Caribbean fishers have succeeded in developing long-lasting, cheap, light FADs for use in deep waters with occasional strong currents. Future research into the technological development of moored FADs would therefore be best focused on advancing the design of light, inexpensive FADs that are easily deployed by fishers themselves. With the help of numerical models, it should be possible to design and build very efficient light FADs using robust new materials.

Despite intensive use of drifting FADs in the Atlantic, Pacific and Indian oceans (Fonteneau et al. 2000b), all studies with FAD design or technology as a primary topic (n $=24$ ) concern moored FADs. The little information that does exist on drifting FAD technology is found in reviews or general papers regarding purse seine fisheries. All purse seine fisheries worldwide use bamboo rafts of about 3 x 1.5 m (Fonteneau et al. 2000b). They are equipped with radiolocation beacons or satellite buoys and are sometimes fitted with additional electronic devices for fish detection. While the number of FADs used by each vessel remains poorly documented, large purse seiners may continuously use more than 100 year-round. In addition, some purse seiners use supply vessels in order to deploy and maintain their FADs, which could be considered as a major increase in the fishing effort of the fleet. As the drifting FADs used aggregate large amounts of fish very efficiently, future technological development should focus upon improving the electronic devices attached to FADs for more accurate estimates of associated fish species and sizes. Such development could both improve the ability of fishers to target specific sizes and species of tuna and potentially aid in minimizing by-catch.

\section{Evolutionary mechanisms driving associative behaviour}

Evidence for the numerous theories forwarded to explain the evolutionary basis of association of fish with floating structures has been reviewed comprehensively by Fréon and Dagorn (2000) and Castro et al. (2002). Fréon and Dagorn (2000) consider the 'indicator-log' hypothesis and the 'meeting-point' hypothesis as most credible and may act in concert to confer adaptive advantage to associative behaviour. The indicator-log hypothesis is based on the precept that natural floating objects more commonly occur in frontal zones, caused by oceanic convergences, and that association with objects will therefore position fish in productive areas. The meeting-point hypothesis states that 'fish make use of animate or inanimate targets to increase the encounter rate between isolated individuals or small schools and other schools in order to constitute bigger schools that are more efficient to the survival of the species' (Fréon and Dagorn 2000). While these hypotheses have considerable merit for some large extranatant and circumnatant species, such as the tunas, it is likely that separate evolutionary mechanisms are more important in the attraction of small juvenile intranatants to drifting structures (Castro et al. 2002).

For intranatants, several hypotheses may better explain associative behaviour (Castro et al. 2002), including protection from predators (Mitchell and Hunter 1970), enhanced feeding opportunities, and onshore transport to habitats suitable for settlement (Kingsford and Choat 1986). A wide variety of studies have provided observational evidence on the importance of structures in reducing predation rates (Gooding and Magnusson 1967, Mitchell 
and Hunter 1970), suggesting that associative behaviour confers significant protection from predators for certain species. While few studies have shown juvenile fish experience enhanced feeding conditions in the vicinity of floating structures, such structures occur in oceanic fronts and coastal plumes (Kingsford 1995) more often than in open water due to current convergences, and such areas are known to enhance feeding opportunities for small juvenile fish (Rissik and Suthers 1996). Transport of small juveniles to coastal areas is likely to be most important for taxa that spawn in offshore waters but have coastal or inshore nurseries for juveniles, as demonstrated for crab megalopa (Shanks 1983) and rocky reef fish species (Kingsford and Choat 1986) associated with drifting algae.

Many of the theories that have been proposed to explain the association of fish with drifting structure are difficult to test experimentally. While patterns of association can be used to infer the validity of some of these theories and modelling studies may provide some insight into the underlying mechanisms of association (e.g. Dagorn and Fréon 1999), conducting experiments on evolutionary time scales is clearly impractical in the open ocean. Almost all experiments are conducted on ecological time scales, which is appropriate to gather information for management of fish stocks, but provides little useful insight into evolutionary mechanisms. While scientists will continue to ask 'why are fish attracted to FADs?', our perspective is that there are far more pressing research needs concerning the current widespread use of FADs in the world's oceans and their effects on fish stocks on an ecological time scale. To address these needs, future FAD research should focus on: 1) describing how fish interact with FADs (spatial and temporal patterns of association with FADs by fish); 2) determining how fish locate and remain associated with FADs (sensory processes) and; 3) establishing the consequences of association with FADs for both individual fish stocks and the wider pelagic ecosystem.

\section{Patterns of association with floating structures}

\section{Biological influences}

Assemblages of pelagic fish at FADs are influenced by numerous biological and physical factors that act over differing temporal and spatial scales. Long-term biological influences include seasonal patterns in the life history of species that associate with FADs and seasonal variability in the availability of FADs themselves, particularly those of natural origins. Seasonal patterns of appearance of fish at FADs are well established and have been observed for both small juvenile and adult fish (Hunter and Mitchell 1967, Rountree 1990, Deudero et al. 1999, Castro et al. 1999). The majority of small juvenile fish that associate with FADs only do so for a certain period of their life history (Parin and Fedoryako 1999), and as such, spawning periods are thought to regulate the appearance of these species around FADs (Kingsford 1992, Deudero et al. 1999). Large fish such as Coryphaena hippurus also occur seasonally around FADs in some areas (Castro et al. 1999, Deudero et al. 1999, Dempster 2004), due to polewards habitat extensions of juveniles into sub-tropical regions when water temperatures are suitable (Norton 1999, Bennett 2001) or migrationary pathways linked to reproductive behaviour in tropical waters (Oxenford 1999).

The availability of natural drifting FADs in the ocean is subject to biological and oceanographic influences, which cause variability in both space and time. Patches of drift algae predominantly occur in coastal waters (Mitchell and Hunter 1970, Kingsford 1992, Kingsford 1995) and some species of drift algae have clear seasonal peaks in abundance related to their reproductive biology (e.g. Sargassum spp: Ida et al. 1967, Kingsford 1992), or 
the seasonality of storms that tear algae from the substrate. Natural drifting FADs in the open ocean also have distinctive spatial and temporal distributions (e.g. Eastern Pacific Ocean, Solana-Sansores 2001), which may reflect the locations of major river mouths and surface ocean currents (Marsac et al. 2000). Information on the distributions on natural FADs in the Atlantic, Pacific and Indian oceans where industrial purse seining for FAD-associated tuna occurs is particularly important to gauge the potential effects of the increased use of artificial FADs. Artificial drifting FADs have been identified as having different distributions to natural drifting FADs (Eastern Pacific Ocean: Marsac et al. 2000). A change in the distribution and abundance of FADs may lead to changes in the way fish are distributed in the ocean and subsequently have broader consequences for certain exploited fish stocks and the pelagic ecosystem (see 'ecological effects' section).

In contrast to long-term biological influences, short-term biological factors that may cause fish assemblages at FADs to vary over hours to weeks are poorly understood. Great variability in the numbers of pelagic fish at moored FADs between sampling times days to weeks apart have been observed often (Rountree 1990, Cillauren 1994, Josse et al. 2000) yet rarely explained, while variability in assemblages at drifting FADs have seldom been examined (although see the observational study of Gooding and Magnusson 1967). Such variability may be related to residence times of certain fish species at FADs, which may in turn be affected by the presence of other fish species through competitive or predator-prey interactions (Deudero 2001). Minimum residence times at FADs have been determined for some fish species through direct observations (drifting FADs: Hunter and Mitchell 1967), conventional tagging (drifting FADs: Takahashi et al. 1988, Hampton and Bailey 1999, moored FADs: Itano and Holland 2000) conventional tagging and 'visual' recapture (moored FADs: Dempster 2003) and ultrasonic tagging and tracking (moored FADs: Holland et al. 1990, Klimley and Holloway 1999). Residence times vary considerably between species, from short periods limited to days (e.g. Coryphaena hippurus, Dempster 2003) or longer periods of weeks to months (e.g. numerous species, Hunter and Mitchell 1968; Kyphosus sectator and Schendopholus ovalis, Castro et al. 1999; Seriola lalandi, Dempster 2003). Further, a single species may show a variety of residence patterns: yellowfin tuna have a range off residence behaviours around FADs, including association with a single FAD over multiple days (Holland et al. 1990), association with a FAD during the day with forays away at night (Holland et al. 1990, Cayre 1991), and repeat visits to the same FAD weeks to months apart (Klimley and Holloway 1999).

Little direct information exists, however, on how residence times vary for individual species under different types of environmental conditions (e.g. prey availability). For some pelagic species that associate with FADs in large schools, such as the FAD-associated tunas, FADs may hold insufficient prey. Studies comparing diets of FAD-associated and unassociated fish indicate that feeding conditions are either poorer (Menard et al. 2000) or modified in the vicinity of FADs (Brock 1985, Buckley and Miller 1994). While FADs may hold little prey, the availability of prey nearby may be important in maintenance of an association. Dagorn et al. (2000b) modelled associations of tuna with FADs and showed that associations were more durable when adequate prey occurred within the detectable area of a FAD. Further studies that combine observations of fish behaviour with simultaneous monitoring of the biological environment are necessary to determine the effect of prey availability on the duration of the association of tunas with FADs (Dagorn et al. 2000a). 


\section{Physical influences}

Oceanographic variability has seldom been taken into account to explain temporal variability in fish assemblages at FADs (Kingsford 1999). Variability in water temperature or current strength may conceivably influence the types of fish that occur at FADs and the durations of their associations. Oceanographic influences may be more important in coastal waters than the open ocean as coastal waters are typically more dynamic. Moreover, physical variability may be more pertinent to assemblages at moored than drifting FADs, as drifting FADs are likely to remain within a particular water mass for longer periods.

Variability in temperature regimes caused by oceanographic events may affect fish assemblages at moored FADs, particularly where temperatures drop below threshold levels for warm-water species (e.g. $19-20^{\circ} \mathrm{C}$ for Coryphaena hippurus: California, Norton 1999; east coast of Australia, Dempster 2004). High wind strengths and wave heights may affect associations by reducing the ability of small intra- and extranatant species to remain with floating objects due to rough surface conditions or greater speed of the object through the water due to wind pushing. Rough sea conditions may also affect the ability of circumnatants to sense FADs from beyond visual range if the sensory cues involved in detection of FADs are altered by such conditions and lead to the break down of aggregations. At present, the influence of sea surface state on aggregations at FADs remains untested.

Current variability at moored FADs may conceivably alter fish assemblages, with small intranatants unable to meet the energetic requirements necessary to remain associated under persistent strong flows. Several studies have presented observational evidence that suggests current direction influences where certain pelagic species are located around moored FADs with respect to the direction of the current (e.g. Klima and Wickham 1971, Rountree 1990). However, despite the frequent use of visual counts to describe aggregations at moored FADs ( $\mathrm{n}=25$ studies, Table 3), no study has measured current strength and determined its effect upon intranatant species. In future, such studies should measure surface currents routinely in conjunction with visual counts. 
Table 3 Experimental methods used by studies of fish aggregation devices from 1960 to 2003. Fishery dependent $=$ studies that used fishery statistics such as catch and effort. Fishery independent $=$ experimental fishing techniques such as catch and strike rates. Other $=$ aging techniques, gonad analysis techniques and questionnaires.

\begin{tabular}{ccc}
\hline Method & No. of studies & \% of total \\
\hline Aquarium experiments & 3 & 1.3 \\
Acoustic surveys & 7 & 3.0 \\
Fishery dependent & 107 & 45.9 \\
Fishery independent & 20 & 8.6 \\
Stomach contents & 10 & 4.3 \\
Modelling & 16 & 6.9 \\
Net sampling & 15 & 6.4 \\
Conventional tagging & 5 & 2.1 \\
Ultrasonic / archival tags & 17 & 7.3 \\
Visual counts & 25 & 10.7 \\
Fich tranclncatinn & 2 & 0.9 \\
Fish translocation & 6 & 2.6 \\
Other & &
\end{tabular}

Current speeds may also affect the behaviour of larger FAD-associated species. Dempster and Kingsford (2003) observed larger aggregations of juvenile dolphinfish (30 - 50 $\mathrm{cm}$ fork length) in visual counts around moored FADs off the east coast of Australia on days when surface currents were strongest $\left(>0.5 \mathrm{~ms}^{-1}\right)$, and attributed this to a behavioral shift towards closer association with FADs rather than to a true indication of increased abundance of dolphinfish in the vicinity of the FAD. In contrast, Kakuma (2000b) recorded greater catches of yellowfin tuna around moored FADs on days when currents were weak $\left(<0.2 \mathrm{~ms}^{-}\right.$ ${ }^{1}$ ), indicating that either aggregations were larger or purse seining was more efficient. In both studies, any possible effect of current may have been confounded by sampling biases inherent in the techniques used to sample fish. Sampling techniques that are equally efficient in determining fish aggregations at differing current speeds or are not influenced by possible changes in fish behaviour as current speeds vary are necessary to test the role of current in aggregation variability. Both population- and individual-based approaches, such as acoustic surveys (e.g. Josse et al. 2000) and ultrasonic-tagging and listening stations (e.g. Klimley and Holloway 1999) respectively, together with depth-stratified current measurements around moored FADs, would be ideally suited to test hypotheses concerning the effect of currents. 
A suite of sensory processes may be involved in pelagic fish being able to find and remain associated with floating structures. These include vision, smell, sound or vibrations, touch and magneto-reception. Separate sensory processes may act in concert and indeed association with FADs may involve a hierarchy of processes operating over differing spatial scales. The sensory processes used by pelagic fish to locate and remain with floating structures may differ with both fish size (small pre-settlement juveniles to large pelagic adults) and type of floating structure (moored or drifting). Moreover, initial location of and continued association of fish with a floating object for short (hrs to weeks: Hunter and Mitchell, 1967) or long periods (months: Klimley and Holloway 1999) may involve separate sensory capabilities and the relative importance of sensory cues in these processes may therefore also differ. The great amount of observational evidence collected allows evaluation of the relative importance of sensory processes for particular species, however, few manipulative experiments have tested the importance of a particular sensory capability (Dempster and Kingsford 2003).

\section{Vision}

Vision appears to be involved in attraction of some species of fish to FADs, although its importance may differ depending upon whether FADs are moored or drifting. Translocation of some small juvenile fish caught at drifting FADs has indicated that fish are capable of returning to FADs when released within visual range, but not when released beyond visual range (Hunter and Mitchell 1967). Little direct information exists regarding the spatial arrangement of larger pelagic species around drifting FADs. While archival tagging suggests bigeye tuna swim at average depths of $33.5 \mathrm{~m}$ beneath FADs during the day and move marginally closer to the surface at night (27.7 m, Schaefer and Fuller 2002), results consistent with bigeye tuna maintaining visual contact, this information cannot be used to determine the role of vision in tuna remaining associated with a FAD in the absence of detailed information on movements in the horizontal plane. The lack of basic information regarding movements and residence times of tuna and tuna-like species around drifting FADs is the most obvious gap in our understanding of the interaction of these fish with FADs. Such information would provide better assessment of the relative importance of the various sensory mechanisms these fish may use to find and remain associated with drifting FADs.

In contrast to drifting FADs, several studies have indicated that a number of pelagic species move distances of hundreds of metres to kilometers away from moored FADs and returned, demonstrating that sensory processes other than vision contribute to FAD detection (translocation experiments: Ibrahim et al. 1990, Dempster and Kingsford 2003; ultra-sonic tracking: Holland et al. 1990, Dagorn et al. 2000a). Ibrahim et al. (1990) found that several coastal pelagic species were capable of reassociating with the FAD they were captured from after displacement to distances up to 150-180 m away. Dempster and Kingsford (2003) found that both Coryphaena hippurus and Seriola lalandi re-associated with FADs after displacement up to $275 \mathrm{~m}$ away in proportions far greater than could be expected if they swam in a random direction from the point of release. Yellowfin tuna (Thunnus albacares) are capable of detection of moored FADs from far greater distances; ultra-sonic tracking studies have demonstrated that tuna can re-locate FADs after swimming 5 to 8 miles away (Holland et al. 1990, Dagorn et al. 2000a). 


\section{Smell}

Our understanding of the role chemical cues play in attraction and association of pelagic fish to drifting structures is largely limited to observations and correlative evidence. For logs and FADs that drift in open water, chemical cues appear to have little bearing on the large pelagic species such as tuna which associate with them, as colonization tends to be rapid (generally < 1 week; Bard et al. 1985, Yu 1992) and catches do not vary with FAD age (Bard et al. 1985). At present no manipulative study has tested the role of chemical cues in attraction of large extranatants to drifting FADs.

Studies on small intranatants have reported association of numerous species in large abundances within hours of deployment of small drifting FADs (e.g. Kingsford 1992, Druce and Kingsford 1995). However, for small juvenile fish with severely restricted visual ranges (Elliott et al. 1995) yet developed chemosensory capabilities (Atema et al. 2002), chemical cues could be important in attraction to drifting objects from distances of 10 s of metres away. Two recent manipulative studies have provided the first evidence that colonization by small intranatants at FADs is influenced by the presence of fouling organisms, suggesting chemical cues enhance attraction (Nelson 2003, Dempster and Kingsford 2004). Nelson (2003) compared colonization of fishes to drifting FADs carrying fouling communities 14 to 22 days old and control FADs, while Dempster and Kingsford (2004) compared colonization between drifting FADs with gooseneck barnacles, Lepas sp., attached and control FADs. Both studies recorded greater abundances of intranatants at FADs over drift times of $3 \mathrm{hr}$ (Dempster and Kingsford 2004) and days (Nelson 2003).

Observational evidence on the role of smell in the attraction of fish to moored FADs is inconclusive. Several studies have observed rapid colonization of pelagic species at moored FADs in the absence of a developed fouling community (Klima and Wickham 1971, Deudero et al. 1999), while other studies have reported greater association of pelagic species at FADs after significant lag times post deployment (Hunter and Mitchell 1968, Chen 1989). Such a lag in establishment of aggregations at FADs could be due to several factors, including a gradual increase in fish numbers over time through random encounter, or chemical cues from fouling on the FAD or associated fish being necessary precursors for the attraction of other fish. Dempster and Kingsford (2003) tested the role of olfactory cues in the re-association of displaced Coryphaena hippurus and Seriola lalandi to moored FADs with developed fouling communities. They transported fish to down-current and across-current sites and monitiored the percentage of fish that returned with conventional tags coloured for individual fish recognition. The experiment relied on the assumption that, with directional flow, an odour trail could result and enhance detection of a FAD from down-current. Both species of fish returned in similar proportions from both the across- and down-current displacement sites, indicating that olfactory cues were not involved in homing for either species over the distances that displacements were made (20 to $500 \mathrm{~m}$ from the FAD).

\section{Sound}

Sound and vibrations are a further obvious set of sensory cues that may enable fish to locate FADs. In water, sound propagates equally in all directions from its source (Hawkins 1993), and may be detectable over spatial scales of metres to kilometres (Kingsford et al. 2002). Fish are capable of hearing sound and can crudely discriminate direction, however, whether they can localize sound with sufficient sensitivity to navigate is uncertain (review: Popper et al. 2002), and little research has been conducted on the hearing capabilities of FAD- 
associated fish. Generally, sound detection by fish is limited to a narrower frequency range than terrestrial vertebrates, especially mammals and birds. Fish can detect sound levels from 50 to $75 \mathrm{~dB}$ at frequencies between 100 and $2000 \mathrm{~Hz}$ (Popper et al. 2002), but are generally insensitive to frequencies over 2 to $3 \mathrm{kHz}$ (except clupeids, Mann et al. 1997). At present, knowledge on the hearing capability of large pelagic fish, such as tuna, remain limited (Iversen 1972). Schooling fish also have excellent abilities to detect vibrations via the lateral line (Blaxter and Batty 1985), which can be used to detect prey at distances beyond visual range (Partridge 1982). This ability may also prove useful in detecting FADs at distance.

Surface wave action and fish associated with FADs may produce sound and vibrations at both moored and drifting FADs. Moored FADs have the added potential to produce sound through movement of the anchor chain and vibration of the mooring line in strong currents. Detection of these low frequency sounds has been suggested as a possible navigational cue for pelagic fish (Marsac and Cayre 1998). However, there is as yet no published information on the sound/vibration climate around moored or drifting FADs. Such data is necessary to determine whether FAD-associated pelagic fish have the physiological capability to detect the frequency of sound emitted by FADs, or fish associated with FADs, and over what distances. At present, our knowledge of the hearing capabilities of large pelagic fish from physiological studies is limited. Until such information is available, the frequencies of sound and over what distance sound emanating from FADs may be detectable by large pelagic fish over background noise are untested assumptions. For the time being, the role of sound and vibrations in attraction of fish to FADs remains an unopened black box.

\section{Magneto-reception}

Magneto-reception is believed to be important for long-distance navigation by both terrestrial and marine animals (Papi 1992), and may be used by large tunas to detect moored FADs (Holland et al. 1990). Yellowfin tuna (Thunnus albacares) possess possible magnetic sense organs (cranial biogenic magnetite; Walker et al. 1984), and their ability to discriminate between magnetic fields of differing intensities has been determined in tank experiments (Walker 1984). However, whether this ability translates to a long-distance navigational capability remains unknown (Walker et al. 1997, Døving and Stabell 2002).

Observational evidence for use of a magnetic sense for long distance navigation and homing to moored FADs by large tuna is compelling. A number of ultra-sonic tracking studies provide extensive evidence that tuna leave and return to moored FADs after forays as distant as 5 to 8 nautical miles (Holland et al. 1990, Marsac and Cayre 1998, Brill et al. 1999). Moreover, tuna may return to the same moored FAD weeks to months after departing (Klimley and Holloway 1999). Moored FADs are relatively stable in space and time compared to drifting FADs and large tuna may be able to associate them with the particular magnetic signature of their location.

Regardless of whether a magnetic sense is involved in detection of moored FADs, its usefulness in detection of drifting FADs is dubious, as the positions of drifting FADs continually vary. Moreover, the geomagnetic signatures of sea floor areas of the open ocean where drifting FADs typically occur are likely to be far less distinguishable than signatures at continental shelf or island margins (e.g. Hawaii, Reunion Island) where moored FADs are typically located. 


\section{Patterns of exploitation}

The association of fish with floating structures is the basis of many fisheries around the world. Over the past two decades, the use of drifting FADs for large-scale industrial fisheries has increased dramatically. Drifting FADs have become an increasingly important tool in the exploitation of tuna since the early 1980s by greatly increasing the fishing efficiency of oceanic purse seiners. Drifting FADs reduce the proportion of nil sets, reduce searching time and increase the flexibility of fishing operations. Tens of thousands of drifting FADs are estimated to be in use by industrial purse seiners worldwide (Fonteneau et al. 2000b). Drifting FADs are also becoming increasingly sophisticated through the addition of electronic devices for fish detection, which may significantly increase the fishing efficiency of purse seine operations. As a consequence of this shift in the operation of the fishery, appropriate estimates of fishing effort for tuna stock management must be continually revised.

While total catches at moored FADs are several orders of magnitude less than at drifting FADs, they are important components of fishery exploitation strategies in many regions. Coastal moored FAD programs now operate in at least 28 countries (Fréon and Dagorn 2000) after many were initiated to provide alternate fishing opportunities for pelagic species, in response to declining demersal fisheries (Taquet 1998). Some correlative evidence suggests such a beneficial effect for demersal stocks may have occurred in certain areas (Plante 1997, Kakuma 2000a). In Okinawa, Japan, catch of demersal species decreased after an extensive FAD program was introduced, although it is unclear whether this was due to previous overfishing of demersal stocks or as a result of a change in fishing effort after FADs were introducted (Kakuma 2000a). Future studies should seek to separate these two potential effects, perhaps by a 'before-after' study assessing shifts in catch and effort of demersal and pelagic fish.

\section{By-catch}

Our analysis of FADbase indicates that the majority of specific research into by-catch at FADs has been published recently (after 1998). Purse seine fisheries at drifting FADs account for the greatest amounts of by-catch taken, as other techniques (e.g. line fishing) around both moored and drifting FADs are more selective of the target species. Some estimates of the level of by-catch taken by purse seiners as a result of fishing at FADs exist (global: > 100000 t by-catch/year; Fonteneau et al. 2000b; Indian Ocean: 27.1 t bycatch/1000 t target species; Romanov 2002; Atlantic Ocean: < 10\% of reported billfish catches; Gaertner et al. 2002), however such estimates are typically limited by observer coverage.

By-catch of certain species may represent a significant ecological problem at the scale of the oceanic purse seine fishery through depletion of stocks of vulnerable species (e.g. pelagic sharks). Negative interactions with smaller scale local fisheries may also occur through reduction of stocks of species that are of little or no value and are discarded by purse seiners, but are comparatively valuable to local small scale fishers.

Future research on by-catch should be focused in two directions. Better information on the actual levels of by-catch is clearly necessary. For example, mechanisms to aid collection 
of by-catch data could be increasing observer coverage and requiring that all fishing operations that use drifting FADs record by-catch. Research should then focus on analysis of this data in order to evaluate the impact of purse seining on vulnerable species and potential flow-on consequences of by-catch by the purse seine fleet for small-scale local fisheries.

\section{Ecological effects}

A gathering body of evidence suggests that the introduction of FADs en masse into the world's oceans and their subsequent use for commercial fisheries may have significant effects upon the pelagic ecosystem (Fonteneau et al. 2000b, Marsac et al. 2000, Essington et al. 2002). Marsac et al. 2000 first highlighted the possibility that FADs may act as an 'ecological trap', by affecting migration routes, modifying the diet of pelagic species, causing prey switching (Brock 1985) or poorer feeding conditions (Menard et al. 2000). Fishing at FADs has also modified the exploited size structure of tuna species, with greater amounts of smaller fish caught around FADs compared to unassociated schools (Fonteneau et al. 2000b), and may alter the distribution of tuna schools in the open ocean (Fonteneau et al. 2000a), as natural drifting objects and man-made drifting FADs have different distributions (Marsac et al. 2000). Further, FAD-based dolphinfish fisheries have sex-specific effects, with proportionally more females caught at FADs than in open waters (Oxenford 1999). Increased use of FADs could also lead to cascading predator-prey effects on the pelagic ecosystem (Essington et al. 2002). As the use of artificial drifting FADs for purse seine fisheries continues to escalate, knowledge of the basic biology and ecology of exploited species, particularly around drifting FADs, will provide better information for management of the impact of FADs on fish stocks and the wider pelagic ecosystem.

The increasing abundance of 'accidental FADs', large floating structures in the world's oceans for reasons other than enhancing pelagic fisheries, such as oil platforms and coastal-sea cage fish farms, may also have significant impacts on pelagic fish stocks in specific areas. Such structures have the potential to modify residence times in a given area, feeding ecology, migrationary pathways of pelagic fish and susceptibility to fishing (Franks 2000, Dempster et al. 2002). While oil platforms and coastal sea-cage fish farms have not typically been thought of in the same context as FADs, they represent large surface structures in open waters and attract large aggregations of pelagic species. Despite the abundance of these structures in certain areas, extraordinarily little is known about impacts upon the wild fish they attract.

The environmental effects of these structures, particularly coastal sea-cage fish farms, have been traditionally thought of as localized to their immediate vicinity, largely due to the dominant focus of environmental impact studies on effects upon the benthos. Such thinking is not applicable to the potential impacts on pelagic fish species that closely associate with these structures, as pelagic fish are typically highly mobile throughout their life history. When the number of structures in a particular area is extensive (e.g. Gulf of Mexico: 4000 oil platforms, Franks 2000; Mediterranean Sea: 500+ coastal sea-cage fish farms, Theodorou 1999, Sanchez-Mata and Mora 2000), the scale of the potential effects becomes evident. In the case of fish farms, such effects may be positive, if wild fish receive significant protection (spatial and temporal) from fishing due to their association with fish farms, or negative, if the close association with farms increases the susceptibility of wild stocks to fishing, parasites or disease (Dempster et al. 2004). Similarly, oil platforms may alter migration routes and increase fishing pressure by aggregating pelagic species (Franks 2000). There is a great need for future studies to document the extent of these impacts to determine how the interaction of 
wild fish with accidental FADs may be managed best. Fish ecologists, and more specifically FAD scientists, have the methodological toolkit to answer many of the pressing questions regarding the impacts of accidental FADs on wild fish populations.

\section{Conclusions and recommendations}

\section{Need for manipulative studies}

As the number of anthropogenic floating structures of all types continues to increase in the world's oceans (drifting FADs: Fonteneau et al. 2000b; moored FADs: Fréon and Dagorn 2000; oil platforms: Franks 2000; coastal sea-cage fish farms: Dempster et al. 2002; rubbish: Riera et al. 1999), knowledge of the patterns, sensory processes and ecological consequences of aggregation of fish at these structures will become increasingly important for management of wild fish stocks. While descriptive studies have contributed greatly to our understanding of patterns of association of pelagic fish with floating structures, we still know relatively little about the underlying evolutionary mechanisms and sensory processes driving attraction. To address these pressing research needs, manipulative experimental approaches must replace the dominance of observational and descriptive studies (Dagorn et al. 2000a).

\section{Drifting vs. Moored FADs}

Our analysis of the literature revealed that the great majority of research has been performed on moored FADs, principally due to difficulties in studying large mobile fish around drifting objects in the open ocean, which are temporary in both space and time. Pelagic fish may treat moored and drifting FADs differently (Holland et al. 1990, Fréon and Dagorn 2000) and sensory cues that enable detection of moored and drifting FADs are likely to differ also. Consequently, information on the ecology of pelagic fish at moored FADs cannot be readily extrapolated to understand ecological processes at drifting FADs.

We extend Dagorn et al.’s (2000a) call for more manipulative experiments, by suggesting that greater priority be given to research of pelagic fish at drifting FADs. Associative behaviour must have evolved around drifting structures that occur naturally in the world's oceans, such as logs, seaweed rafts and jellyfish, as the presence of moored structures in the open ocean is a modern phenomenon. Moreover, drifting FADs are the basis for far larger fisheries ( $\approx 1.2$ million tons of tuna per year, Alain Fonteneau pers. comm.) than moored FADs. Therefore, research on drifting FADs, despite inherent practical difficulties, is far more important for both fundamental understanding of pelagic fish behaviour and fisheries management practices.

Little information on the behaviour and patterns of use of pelagic fish around drifting FADs exists (but see Schaefer and Fuller 2002), although we now have the technical capacity to gather much of this data through advanced tagging and acoustic techniques. Further development of remote data collecting capabilities to better describe aggregations of pelagic fish at drifting FADs is currently occurring through the 'FADIO' program (http://www.fadio.ird.fr). Such information is essential to assess the susceptibility of tuna and by-catch pelagic species to overfishing due to their associations with FADs and the widespread use of FADs by the oceanic purse seine fleet. 
Detailed information of the sensory capabilities of pelagic fish, and more specifically information that relates to their ability to sense FADs, is almost completely lacking. Physiological studies to develop such information are a vital first step in researching how fish locate and remain associated with FADs. Without such information, researchers may investigate potential mechanisms that are beyond the physiological abilities of the fish. For example, sound is currently favoured as a possible cue for detection of FADs by fish (Marsac and Cayre 1998, Dempster and Kingsford 2003). However, we do not know what frequencies of sound large pelagic species (such as tuna) can sense, and over what distances, and if these frequencies match sounds emanating from FADs or schools of fish associated with FADs. For practical reasons, such physiological studies could first be done in controlled experimental environments such as tanks or large aquaculture sea cages.

Once the physiological capabilities of FAD-associated species are better known, specific in situ experiments that manipulate the sensory cues of FADs or the sensory capabilities of fish are required and could be coupled with remote collection of data through electronic tagging. Experimental manipulations of the sensory capabilities of pelagic fish that minimize stress would be preferable. For example, vision of pelagic fish could be modified by blindfolding, smell could be blocked through injection of a biologically neutral fast-setting compound into the nares (Dempster and Kingsford 2003), or possible magneto-reception capabilities could be modified by attaching small magnets to pelagic fish. In all such experiments, adequate controls could be made. Alternately, FADs could be modified by adding olfactory, auditory or magnetic cues. The methodology and analyses of Leis et al. (2002), who investigated the behaviour of ready-to-settle pelagic juveniles of reef fish in response to sound in the oceanic environment, could be instructive on how to conduct similar studies on larger pelagic fish.

\section{Change in focus for FAD scientists and funding agencies}

Our analysis of FADbase highlights the enormous mismatch between the amount and value of tuna caught around FADs (2003 estimate: amount $\approx 1.2$ million tons, landed value $\approx$ 720 million Euros, Alain Fonteneau pers. comm.) and the amount of research conducted on the use and effects of FADs. Of the 407 papers contained in FADbase, perhaps only a core 100 or so have greatly advanced our knowledge of the interaction of fish with FADs. Specifically for drifting FADs, key papers number but a few dozen, which represents a small fraction of the global research output on tunas and other important large pelagic species. A search of the ASFA database combining 'tuna' and 'fishery' or 'fisheries' illustrates this; over 6700 such articles have been published since 1978. We estimate that FAD research is currently being undertaken by less than 10 full-time scientists around the world, with but a handful researching drifting FADs. A 'paradigm shift' in the focus of both pelagic fisheries scientists, management and funding agencies is required to re-focus both human and monetary resources on research of the use of and effects of drifting FADs. 


\section{Acknowledgements}

We would like to thank the French Embassy in Australia that provided funding to facilitate our scientific collaboration. Annick Radenac and Marielle Bouildé from the IFREMER library (Nantes) assisted with literature searches and Catherine Coriou (IFREMER) made FADbase available on the internet. Alain Fonteneau (IRD) kindly provided information on the estimated global catch and value of tuna and FAD-associated tuna. We thank Jean-Yves Le Gall (ENSAR) and Brigitte Milcendeau (IFREMER) for improving earlier versions of the manuscript. 


\section{References}

Ahilan B., Sujathkumar N.V., Sanjeeviraj G., (1995) Training needs of fishermen in Chidambaranar District, Tamil Nadu (India). Proceedings of the National Symposium on Technological Advancements in Fisheries and its Impact on Rural Development, held at Cochin by School of Industrial Fisheries, Cochin University of Science and Technology during December 5 to 7, 1995, 572-577.

Anderson J. and Gates P.D. (1997) Manuel de la Commission du Pacifique Sud sur les dispositifs de concentration de poissons (DCP). Programme pêche côtière, section techniques de pêche. Planification de programmes DCP, Vol. 1, 46 p.

Atema J., Kingsford M.J. and Gerlach G. (2002) Larval reef fish could use odour for detection, retention and orientation to reefs. Mar. Ecol. Prog. Ser. 241, 151-160.

Au D.W. (1991) Polyspecific nature of tuna schools: Shark, dolphin, and seabird associates. Fish. Bull. vol. 89, n³, 343-354.

Bard F.-X., Stretta J.-M. and Slepoukha M. (1985) Les Epaves artificielles comme auxiliaries de la peche thoniere en ocean atlantique. quel avenir? La Peche Maritime, Oct. 1985, 655659.

Bennett J. (2001) The ecology of dolphin fish (Coryphaena hippurus) off the coast of New South Wales, inferred from tag and release data. Honours thesis, University of New South Wales.

Bergstrom M. (1983) Review of experiences with and present knowledge about fish aggregating devices. Bay of Bengal Programme, Development of Small-Scale Fisheries. FAO report $\mathrm{BOBP} / \mathrm{WP} / 23,57 \mathrm{p}$.

Biais G. and Taquet M. (1990a) Dispositifs de concentration de poisons à la Reunion. Equinoxe 34, 20-26.

Biais G. and Taquet M. (1990b) Dispositifs de concentration de poissons autour de l'île de la Réunion. Rapport interne de la Direction des Ressources Vivantes de l'IFREMER, RIDRV90.05-RH/La Réunion, 34 p.

Blaxter J.H.S. and Batty R.S. (1985) Herring behaviour in the dark: responses to stationary and continuously vibrating obstacles. J. Mar. Biol. Assoc. U.K. 65(4), 1031-1049.

Boy R.L. and Smith B.R. (1984) Design improvements to fish aggregation device (FAD) mooring systems in general use in Pacific Island countries. South Pacific Commission, Handbook No. 24, 77 p.

Boyra A., Sanchez-Jerez P., Tuya F., Espino F. and Haroun R. (2004) Attraction of wild coastal fishes to Atlantic subtropical cage fish farms, Gran Canaria, Canary Islands. Env. Biol. Fish 70(4): 393-401. 
Brill R.W., Block B.A., Boggs C.H., Bigelow K.A., Freund E.V. and Marcinek D.J. (1999) Horizontal movements and depth distribution of large adult yellowfin tuna (Thunnus albacares) near the Hawaiian Islands, recorded using ultrasonic telemetry: implications for the physiological ecology of pelagic fishes. Mar. Biol. 133, 395-408.

Brock R.E. (1985) Preliminary study of the feeding habits of pelagic fish around Hawaiian fish aggregation devices or can fish aggregation devices enhance local fisheries productivity? Bull. Mar. Sci. 37(1), 40-49.

Brodeur R.D. (1998) In situ observations of the association between juvenile fishes and scyphomedusae in the Bering Sea. Mar. Ecol. Prog. Ser. 163, 11-20.

Buckley R.M., Itano D.G. and Buckley T.W. (1989) Fish aggregation device (FAD) enhancement of offshore fisheries in American Samoa. Bull. Mar. Sci. 44, 942-949.

Buckley T.W. and Miller B.S. (1994) Feeding habits of yellowfin tuna associated with fish aggregation devices in American Samoa. Bull. Mar. Sci. 55, 445-459.

Castro J.J., Santiago J.A. and Hernandez-Garcia V. (1999) Fish associated with fish aggregation devices off the Canary Islands (Central-East Atlantic) Sci. Mar. 63(3-4), 191-198.

Castro J.J., Santiago J.A. and Santana-Ortega A.T. (2002) A general theory on fish aggregation to floating objects: an alternative to the meeting point hypothesis. Rev. Fish. Biol. Fisheries 11(3), 255-277.

Cayre P. (1991) Behaviour of yellowfin tuna (Thunnus albacares) and skipjack tuna (Katsuwonus pelamis) around fish aggregating devices (FADs) in the Comoros Islands as determined by ultrasonic tagging. Aquat. Liv. Resour. 4, 1-12.

Cayré P., De Reviers X. and Venkatasami A. (1991) Practical and legal aspects of settlement and exploitation of fish aggregating devices (FADs). Symposium on Artificial Reefs and Fish Aggregating Devices as Tools for the Management and Enhancement of Marine Fishery Resources, Colombo, Sri Lanka, 14-17 May 1990. FAO, RAPA Report 1991/11, 75-82.

Chapman L. (2000) Small-scale FADs-associated fishing techniques used in the Pacific region. In: Le Gall J.-Y., Cayre P. and Taquet M. (eds), Pêche thonière et dispositifs de concentration de poisons. Ed. Ifremer, Actes Colloq. 28, 346-355.

Chen S.-R. (1989) Study on aggregation effect of artificial floating reef. J. Fish. Soc. Taiwan 16(1), 29-46.

Cillauren E. (1994) Daily fluctuations in the presence of Thunnus albacares and Katsuwonus pelamis around fish aggregating devices anchored in Vanuatu, Oceania. Bull. Mar. Sci. 53(23), 581-591.

Dagorn L. and Freon P. (1999) Tropical tuna associated with floating objects: a simulation study of the meeting point hypothesis. Can. J. Fish. Aquat. Sci. 56, 984-993. 
Dagorn L., Josse E. and Bach P. (2000a) Individual differences in horizontal movements of yellowfin tuna (Thunnus albacares) in nearshore areas is French Polynesia, determined using ultrasonic telemetry. Aquat. Liv. Resour. 13, 193-202.

Dagorn L., Josse E., Bach P. and Bertrand A. (2000b) Modeling tuna behaviour near floating objects: from individuals to aggregations. Aquat. Liv. Resour. 13, 203-211.

D'Anna G., Badalamenti F. and Riggio S. (1999) Traditional and experimental floating fish aggregating devices in the Gulf of Castellamare (NW Sicily): results from catches and visual observations. Sci. Mar. 63(3-4), 209-218.

Dempster T., Sanchez-Jerez P., Bayle-Sempere J.T., Giménez-Casalduero F. and Valle C. (2002). Attraction of wild fish to sea-cage fish farms in the south-western Mediterranean Sea: spatial and short-term temporal variability. Mar. Ecol. Prog. Ser. 242, 237-252.

Dempster T. (2003) Association of pelagic fish with floating structures: patterns, processes and ecological consequences. PhD thesis, University of Sydney.

Dempster T. and Kingsford M.J. (2003) Homing of pelagic fish to fish aggregating devices (FADs): an investigation of the role of sensory cues. Mar. Ecol. Prog. Ser. 258, 213-222.

Dempster T. (2004) Biology of fish associated with fish aggregation devices (FADs): implications for the development of a FAD-based fishery in New South Wales, Australia. Fish. Res. 68(1-3), 189-201.

Dempster T. and Kingsford M.J. (2004) Drift objects as presettlement habitat for pelagic juvenile fish off New South Wales, Australia. Marine and Freshwater Research (in press)

Dempster T., Sanchez-Jerez P., Bayle-Sempere J. and Kingsford M (2004) Extensive aggregations of wild fish at coastal sea-cage fish farms. Hydrobiologia (in press)

Desumont A. (2000) FAD models developed by SPC: review and future prospects. In: Le Gall J.-Y., Cayre P. and Taquet M. (eds), Peche thoniere et dispositifs de concentration de poisons. Ed. Ifremer, Actes Colloq. 28, 276-289.

Desurmont A. and Chapman L. (2000) The use of anchored FADs in the area served by the Secretariat of the Pacific community (SPC): Regional synthesis. In: Le Gall J.-Y., Cayre P. and Taquet M. (eds), Peche thoniere et dispositifs de concentration de poisons. Ed. Ifremer, Actes Colloq. 28, 108-140.

Deudero S. (2001) Interspecific trophic relationships among pelagic fish species underneath FADs. J. Fish. Biol. 58, 53-67.

Deudero S., Merella P., Morales-Nin B., Massuti E. and Alemany F. (1999) Fish communities associated with FADs. Sci. Mar. 63(3-4), 199-207. 
Døving K. and Stabell O.B. (2002) Trails in open water: sensory cues in salmon migration. In: Collin S.P. and Marshall N.J. (eds), Sensory processing in aquatic environments. SpringerVerlag, New York, pp. 39-52.

Druce B.E. and Kingsford M.J. (1995) An experimental investigation of the fishes associated with drifting objects in coastal waters of temperate Australia. Bull. Mar. Sci. 57(2), 378-392.

Elliott J.K., Elliott J.M. and Marsical R.N. (1995) Host selection, location, and association behaviors of anemonefishes in field settlement experiments. Mar. Biol. 122, 377-389.

Essington T.E., Schindler D.E., Olson R.J., Kitchell J.F., Boggs C. and Hilborn R. (2002) Alternative fisheries and the predation rate of yellowfin tuna in the eastern Pacific Ocean. Ecol. App. 12(3), 724-734.

FAO (2002) Fishstat Plus. Capture production 1970-2002. FAO, Rome. www.fao.org/fi/statist/FISOFT/FISHPLUS.asp.

Franks J.S. (2000) A review: pelagic fishes at petroleum platforms in the northern Gulf of Mexico; diversity, interrelationships and perspectives. In: Le Gall J.-Y., Cayre P. and Taquet M. (eds), Peche thoniere et dispositifs de concentration de poisons. Ed. Ifremer, Actes Colloq. 28, 502-515.

Freon P. and Dagorn L. (2000) Review of fish associative behaviour: toward a generalisation of the meeting point hypothesis. Rev. Fish. Biol. Fisheries 10, 183-207.

Fonteneau A., Ariz J., Gaertner D., Nordstrom V. and Pallares P. (2000a) Observed changes in the species composition of tuna schools in the Gulf of Guinea between 1981 and 1999, in relation with the Fish Aggregating Device fishery. Aquat. Liv. Resour. 13, 253-257.

Fonteneau A., Pallares P. and Pianet R. (2000b) A worldwide review of purse seine fisheries on FADs. In: Le Gall J.-Y., Cayre P. and Taquet M. (eds), Peche thoniere et dispositifs de concentration de poisons. Ed. Ifremer, Actes Colloq. 28, 15-34.

Gaertner D., Menard F., Develter C., Ariz J. and de Molina A.D. (2002) Bycatch of billfishes by the European tuna purse-seine fishery in the Atlantic ocean. Fish. Bull. 100(4), 683-689.

Galea J.A. (1961) The ‘Kannizzati’ Fishery. Proc. Gen. Fish. Counc. Med. 55, 85-91.

Gates P.D., Cusack P. and Watt P. (1996) South Pacific Commission Fish Aggregating Device (FAD) manual, Volume 2, Rigging deep-water moorings. Coastal Fisheries Programme, SPC, Noumea. 43 p.

Gooding R.M. and Magnusson J.J. (1967) Ecological significance of a drifting object to pelagic fishes. Pac. Sci. 21, 486-497.

Greenblatt P.R. (1979). Associations of tuna with flotsam in the eastern tropical Pacific. Fish. Bull. 77(1), 147-155.

Guillou A., Bruyère F. and Lagin A. (1995) Activités nouvelles de pêche autour des DCP profonds à la Martinique : comparaison des résultats obtenus avec ceux de la pêche au large 
traditionnelle à Miquelon. Rapport de contrat d’étude IFREMER/Comité des Pêches - Région Martinique n 94/1212127, 58 p.

Hampton J. and Bailey K. (1999) Fishing for tunas associated with floating objects: a review of the Western Pacific fishery. In: Scott M.D., Bayliff W.H., Lennert-Cody C.E. and Schaefer K.M. (eds.), Proceedings of the international Workshop on the Ecology and Fisheries for Tunas Associated with Floating Objects, February 11-13, 1992. Inter-American Tropical Tuna Commission Special Report 11, La Jolla, California, pp. 222-284.

Hawkins A.D. (1993) Underwater sound and fish behaviour. In: Pitcher T.J. (ed.), Behaviour of teleost fishes. $2^{\text {nd }}$ ed. Chapman and Hall, London, pp. 129-169.

Heyerdahl T. (1950) The Kon-tiki expedition: by raft across the south seas. George Allen and Unwin Ltd, London.

Higashi G.R. (1994) Ten years of fish aggregation device (FAD) design development in Hawaii. Bull. Mar. Sci. 55(2-3), 651-666.

Holland K.N., Brill R.W. and Chang R.K.C. (1990) Horizontal and vertical movements of yellowfin and bigeye tunas associated with Fish Aggregating Devices. Fish. Bull. 88, 493507.

Holland K.N., Jaffe A. and Cortez W. (2000) The fish aggregating device (FAD) system of Hawaii. In: Le Gall J.-Y., Cayre P. and Taquet M. (eds), Peche thoniere et dispositifs de concentration de poisons. Ed. Ifremer, Actes Colloq. 28, 55-62.

Hunter J.R. and Mitchell C.T. (1967) Association of fishes with flotsam in the offshore waters of central America. Fish. Bull. 66(1), 13-29.

Hunter J.R. and Mitchell C.T. (1968) Field experiments on the attraction of pelagic fish to floating objects. J. Cons. Perm. Int. Explor. Mer. 31(3), 427-434.

Ibrahim S., Kawamura G. and Ambak M.A. (1990) Effective range of traditional Malaysian FAD as determined by fish releasing method. Fish. Res. 9, 299-306.

Ida, H., Hiyama Y. and Kusaka T. (1967) Study on fishes gathering around floating seaweed - I. Abundance and species composition. Bull. Jap. Soc. Sci. Fish. 33(10), 923-929.

Itano D.G. and Holland K.N. (2000) Movement and vulnerability of bigeye (Thunnus obesus) and yellowfin tuna (Thunnus albacares) in relation to FADs and natural aggregation points. Aquat. Liv. Resour. 13, 213-223.

Iversen R.T.B. (1969) Auditory thresholds of the scombrid fish, Euthynnus affinis, with comments on the use of sound in tuna fishing. FAO Fish. Rep. 62(3), 849-859.

Josse E., Dagorn L. and Bertrand A. (2000) Typology and behaviour of tuna aggregations around fish aggregating devices from acoustic surveys in French Polynesia. Aquat. Liv. Resour. 13, 183-192. 
Kakuma S. (2000a) Synthesis on moored FADs in the North West Pacific region. In: Le Gall J.-Y., Cayre P. and Taquet M. (eds), Peche thoniere et dispositifs de concentration de poisons. Ed. Ifremer, Actes Colloq. 28, 63-77.

Kakuma S. (2000b) Current, catch and weight composition of yellowfin tuna with FADs off Okinawa Island, Japan. In: Le Gall J.-Y., Cayre P. and Taquet M. (eds), Peche thoniere et dispositifs de concentration de poisons. Ed. Ifremer, Actes Colloq. 28, 492-501.

Kaneda Y. (1986) Nohon gyogu gyoho zusetsu (Fishing gears and methods in Japan). Seisando, Japan.

Kingsford M.J. (1992) Drift algae and small fish in the coastal waters of northeastern New Zealand. Mar. Ecol. Prog. Ser. 80, 41-55.

Kingsford M.J. (1993) Biotic and abiotic structure in the pelagic environment: importance to small fish. Bull. Mar. Sci. 53, 393-415.

Kingsford M.J. (1995) Drift algae: a contribution to near-shore habitat complexity in the pelagic environment and an attractant for fish. Mar. Ecol. Prog. Ser. 116, 297-301.

Kingsford M.J. (1999) Fish attraction devices (FADs) and experimental designs. Sci. Mar. 63(3-4), 181-190.

Kingsford M.J. and Choat J.H. (1986) Influence of surface slicks on the distribution and onshore movements of small fish. Mar. Biol. 91, 161-171.

Kingsford M., Leis J., Shanks A., Lindeman K., Morgan S. and Pineda J. (2002) Sensory environments, larval abilities and local self-recruitment. Bull. Mar. Sci. 70(1), 341-375.

Klima E.F. and Wickham D.A. (1971) Attraction of coastal pelagic fishes with artificial structures. Trans. Amer. Fish. Soc. 100(1), 86-99.

Klimley A.P. and Holloway C.F. (1999) School fidelity and homing synchronicity of yellowfin tuna Thunnus albacares. Mar. Biol. 133, 307-317.

Kojima S. (1956) Fishing for dolphins in the western part of the Japan Sea. II. Why do the fish take shelter under floating materials? Bull. Jap. Soc. Sci. Fish. 21, 1049-1052.

Le Gall J.-Y., Cayre P. and Taquet M. (2000) Peche thoniere et dispositifs de concentration de poisons. Ed. Ifremer, Actes Colloq. 28.

Leis J.M., Carson-Ewart B.M. and Cato D.H. (2002) Sound detection in situ by the larvae of a coral-reef damselfish (Pomacentridae). Mar. Ecol. Prog. Ser. 232, 259-268.

Leproux E. (2000) Technological evolution of Fish Aggregating Devices (FADs) in French Polynesia. In: Le Gall J.-Y., Cayre P. and Taquet M. (eds), Peche thoniere et dispositifs de concentration de poisons. Ed. Ifremer, Actes Colloq. 28, 290-303.

Mann D.A., Lu Zhongmin and Popper A.N. (1997) A clupeid fish can detect ultrasound. Nature 389, 341. 
Manseuti R. (1963) Symbiotic behaviour between small fishes and jellyfishes with new data on that between the stromateid, Peprilus alepidotus, and the Scyphomedusae, Chryasaora quinquecirrha. Copeia 1963, 40-80.

Marsac F. and Cayre P. (1998) Telemetry applied to behaviour of yellowfin tuna (Thunnus albacares, Bonnaterre, 1788) movements in a network of fish aggregating devices. Hydrobiologia 371/372, 155-171.

Marsac F., Fonteneau A. and Menard F. (2000) Drifting FADs used in tuna fisheries: an ecological trap? In: Le Gall J.-Y., Cayre P. and Taquet M. (eds), Pêche thonière et dispositifs de concentration de poisons. Ed. Ifremer, Actes Colloq. 28, 537-552.

Marcille J. (1979) Nouvelles techniques pour développer la pêche thonière à partir des territoires français du Pacifique Sud. Résultats des essais effectués par la Pacific Tuna Development Foundation. Pêche marit. 1219, 590-594.

Massueti E. and Morales-Nin B. (1999) Biology and fishery of dolphinfish and related species. Sci. Mar. 63(3-4), 181-475.

Matsumoto W.M., Kazama T.K. and Aasted D.C. (1981) Anchored fish aggregation devices in hawaiian waters. Mar. Fish. Rev. 43(9), 1-13.

Menard F., Stequert B., Rubin A., Herrera M. and Marchal E. (2000) Food consumption of tuna in the Equatorial Atlantic ocean: FAD-associated versus unassociated schools. Aquat. Liv. Resour. 13, 233-240.

Minet J.P. and Taquet M. (1993) La pêche artisanale mahoraise - Implantation des dispositifs de concentration de poissons. - Rapport de convention Ifremer/Collectivité Territoriale de Mayotte no. 91/1211331F, 20 p.

Mitchell C.T. and Hunter J.R. (1970) Fishes associated with drifting kelp, Macrocystis pyrifera, off the coast of southern California and northern Baja California. Calif. Fish and Game 56(4), 288-297.

Morales-Nin B., Cannizzaro L., Massuti E., Potoschi A. and Andaloro F. (2000) An overview of the FADs fishery in the Mediterranean Sea. In: Le Gall J.-Y., Cayre P. and Taquet M. (eds), Peche thoniere et dispositifs de concentration de poisons. Ed. Ifremer, Actes Colloq. 28, 184-207.

Murdy E.O. (1980) The commercial harvesting of tuna-attracting payaos: a possible boon for small-scale fishermen. ICLARM Newsletter 1, 10-12.

Nakamae A. (1991) Artificial reef projects in Japan. Symposium on Artificial Reefs and Fish Aggregating Devices as Tools for the Management and Enhancement of Marine Fishery Resources. Colombo, Sri Lanka, 14-17 May, 1990. Rapa Report 1991/11, 244-250.

Nelson P.A. (2003) Marine fish assemblages associated with fish aggregating devices (FADs): the effects of fish removal, FAD size, fouling communities, and prior recruits. Fish. Bull. 101, 835-850. 
Norton J.G. (1999) Apparent habitat extensions of dolphin-fish (Coryphaena hippurus) in response to climate transients in the California Current. Sci. Mar. 63(3-4), 239-260.

Oxenford H.A. (1999) Biology of the dolphin-fish (Coryphaena hippurus) in the western central Atlantic. Sci. Mar. 63(3-4), 277-301.

Papi F. (1992) General aspects. In: Papi F (ed.) Animal Homing. Chapman and Hall, London, pp. 1-18.

Parin N.V. and Fedoryako B.I. (1999) Pelagic fish communities around floating objects in the open ocean. In: Scott M.D., Bayliff W.H., Lennert-Cody C.E. and Schaefer K.M. (eds.), Proceedings of the international Workshop on the Ecology and Fisheries for Tunas Associated with Floating Objects, February 11-13, 1992. Inter-American Tropical Tuna Commission Special Report 11, La Jolla, California, pp. 447-458.

Partridge B.L. (1982) The structure and function of fish schools. Sci. Am. 246(6), 90-99.

Pepperell J. (2001) Fatal Attraction. In: Bluewater magazine.

http://www.bluewatermag.com.au/dec02feature2.asp

Plante R. (1997) The coelocanthe: a reprieve for a fossil. Oceanorama 27, 16-18.

Popper A., Fay R., Platt C. and Sand O. (2002) Sound detection mechanisms and capabilities of teleost fishes. In: Collin S.P. and Marshall N.J. (eds), Sensory processing in aquatic environments. Springer-Verlag, New York, pp. 3-38.

Preston G.L. (1991) Fish Aggregation Devices in the Pacific Islands region. Symposium on Artificial Reefs and Fish Aggregating Devices as Tools for the Management and Enhancement of Marine Fishery Resources, Colombo, Sri Lanka, 14-17 May 1990. Rapa Report 1991/11, 279-294.

Ray-Valette H., Cillauren E. and David G. (2000) Evaluation pluridisciplinaire de la durabilite des pecheries artisanales autuor des dispositifs de concentration des poisons. Aquat. Liv. Resour. 13, 241-252.

Reynal L., Van Buurt G. and Taquet M. (2000) Prospects for the development of anchored FADs in the Lesser Antilles. The case of three islands: Guadeloupe, Martinique and Curacao. In: Le Gall J.-Y., Cayre P. and Taquet M. (eds), Pêche thonière et dispositifs de concentration de poisons. Ed. Ifremer, Actes Colloq. 28, 36-54.

Riera F., Grau A., Grau A.M., Pastor E., Quetglas A. and Pou S. (1999) Ichthyofauna associated with drifting floating objects in the Balearic Islands (western Mediterranean). Sci. Mar. 63(3-4), 229-235.

Rissik D. and Suthers I.M. (1996) Feeding in a larval fish assemblage: the nutritional significance of an estuarine plume front. Mar. Biol. 125, 233-240.

Romanov E.V. (2002) Bycatch in the tuna purse-seine fisheries of the western Indian Ocean. Fish. Bull. 100(1), 90-105. 
Roullot J., Venkatasami A. and Soondron S. (1988) Dispositifs de concentration des poisons (DCP), l'experience Mauricienne. In: Collective volume of working documents presented at the expert consultation on the stock assessment of tunas in the Indian Ocean, Colombo, Sri Lanka, 4-8 December 1986. Doc. No. TWS/86/26. FAO/IPTP, Colombo, Sri Lanka, pp. 233250.

Rountree R.A. (1990) Community structure of fishes attracted to shallow water fish aggregation devices off South Carolina, USA. Env. Biol. Fish. 29, 241-262.

Sacchi J. and Tessier E. (2000) Analysis of FADs loss reasons in La Reunion (Indian Ocean). In: Le Gall J.-Y., Cayre P. and Taquet M. (eds), Peche thoniere et dispositifs de concentration de poisons. Ed. Ifremer, Actes Colloq. 28, 250-260.

Safran P. and Omori M. (1990) Some ecological observations of fishes associated with drifting seaweed off Tohoku coast, Japan. Mar. Biol. 105, 395-402.

Sanchez-Mata A. and Mora J. (2000) A review of marine aquaculture in Spain: production, regulations and environmental monitoring. J. App. Ichthyol. 16, 209-213.

Schaefer K.M. and Fuller D.W. (2002) Movements, behaviour, and habitat selection of bigeye tuna (Thunnus obesus) in the eastern equatorial Pacific, ascertained through archival tags.

Fish. Bull. 100, 765-788.

Shanks A.L. (1983) Surface slicks associated with tidally forced internal waves may transport pelagic larvae of benthic invertebrates and fishes shorewards. Mar. Ecol. Prog. Ser. 24, 289295.

Solana-Sansores R. (2001) Floating objects of the Eastern Pacific: types, spatial distribution and temporal changes. Cienc. Mar. 27(3), 423-443.

Takahashi M., Urakawa T., Kasahara F. and Kanda A. (1988) JAMARC’s activities on tagging on tunas in Indian Ocean. Expert consultation on stock assessments of tunas in the Indian Ocean, Mauritius, 22-27 June 1988. IPTP Collect. Vol. Work. Doc. 3, 208-223.

Taquet M. (1998) The fish aggregating device (FAD): an alternative to the great fishing pressure on reef resources in Martinique. Proc. Gulf Carib. Fish. Inst. 50, 248-261.

Taquet M., Reynal L. and Laurans M. (2000) Do FADs influence the geographical distribution of dolphinfish (Coryphaena hippurus)? In: Le Gall J.-Y., Cayre P. and Taquet M. (eds), Peche thoniere et dispositifs de concentration de poisons. Ed. Ifremer, Actes Colloq. 28, 528-536.

Tessier E., Rey-Valette H., Ah-Nieme D., Bargain R.M., Venkatasamy A. and Wendling B. (2000) Halieutic systems and FADs in the Indian ocean: a review of the various trials carried out and the results obtained in terms of integration and overall benefits. In: Le Gall J.-Y., Cayre P. and Taquet M. (eds), Peche thoniere et dispositifs de concentration de poisons. Ed. Ifremer, Actes Colloq. 28, 159-183. 
Theodorou J. (1999) Greece focuses on marketing seabass and seabream. Seafood Int. 14, 3536.

Torres A. (2000) Guam Fish Aggregating Device programme. In: Le Gall J.-Y., Cayre P. and Taquet M. (eds), Peche thoniere et dispositifs de concentration de poisons. Ed. Ifremer, Actes Colloq. 28, 304-318.

van Buurt G. (2000) Implementation of an ongoing FAD programme in Curacao (Netherlands Antilles) during the period 1993-2000. In: Le Gall J.-Y., Cayre P. and Taquet M. (eds), Peche thoniere et dispositifs de concentration de poisons. Ed. Ifremer, Actes Colloq. 28, 230-249.

Vega M.J.M. (1988) Who's working on fish aggregating devices. Naga, Vol. 11, n², 16p.

Walker M.M. (1984) Learned magnetic field description in the yellowfin tuna, Thunnus albacares. J. Comp. Physiol. A 155, 673-679.

Walker M.M., Kirschvink J.L. and Dizon A.E. (1984) A candidate magnetic sense organ in the yellowfin tuna, Thunnus albacares. Science 224, 751-753.

Walker M.M., Diebel C.E., Haugh C.V., Pankhurst P.M., Montgomery J.C. and Green C.R. (1997) Structure and function of the vertebrate magnetic sense. Nature 390, 371-376.

Wendling B. and Le Calvé S. (2000) Technology and use of anchored FADs in the territorial water from the French Republic's Collectivity of Mayotte (Indian Ocean). In: Le Gall J.-Y., Cayre P. and Taquet M. (eds), Peche thoniere et dispositifs de concentration de poisons. Ed. Ifremer, Actes Colloq. 28, 261-275.

Wickham D.A., Watson J.W.J. and Ogren L. (1973) The efficacy of midwater artificial structures for attracting pelagic sport fish. Trans. Amer. Fish. Soc. 3, 563-572.

Yahaya J (1994) Fish aggregating devices (FADs) and community-based fisheries management in Malaysia. Socio-economics issues in coastal fisheries management. Proceedings of the IPFC symposium in conjunction with the twenty-fourth session of IPFC, Bangkok, Thailand, 23-26 November 1993. FAO, RAPA Publ. №8 : 315-326. 